\title{
Risk factors for meningitis in neurosurgical patients with cerebrospinal fluid drains: prospective observational cohort study
}

\author{
Khetam Hussein ${ }^{1}$ (1) $\cdot$ Galit Rabino ${ }^{1} \cdot$ Omri Feder $^{2} \cdot$ Haneen Eghbaryeh $^{2} \cdot$ Hiba Zayyad $^{1} \cdot$ Gil Sviri $^{2,3} \cdot$ Rima Benenson $^{1} \cdot$ \\ Mical Paul ${ }^{1,2}$
}

Received: 6 November 2018 / Accepted: 4 January 2019 / Published online: 22 January 2019

(C) Springer-Verlag GmbH Austria, part of Springer Nature 2019

\begin{abstract}
Background Cerebrospinal fluid (CSF) drainage or intracranial pressure (ICP) monitoring devices are life-saving devices. We examined the risk factors for infections related to them and assessed the effect of an infection control (IC) intervention.

Methods A prospective observational study was conducted in the Neurosurgical Department of our hospital between 2014 and 2017. We included all consecutive patients undergoing CSF catheter insertions, including external ventricular drainage (EVD), lumbar drainage (LD), and ICP catheters. An IC intervention was implemented between March and August 2016. We examined risk factors for meningitis or ventriculitis, defined according to Healthcare-associated infections surveillance definitions, on univariate and multivariate analysis.

Results A total of 232 patients with 437 drains (212 EVDs, 92 LDs, and 133 ICPs) were included. On univariate and multivariate analysis, the infection incidence was 13.7 per 1000 drain days (17.3/1000 before IC intervention, 7.9/1000 during, and 9.2/1000 after the intervention). Most episodes were caused by Gram-negative bacteria, and the most common pathogen was Acinetobacter baumanii. Risk factors for infection per patient included diabetes mellitus ( $p=0.017)$, CSF leak $(p=0.032)$, drain opening $(p=0.027)$, and the duration of the drain in days $(p=0.035)$. Risk factors per catheter included drain opening $(p<0.001)$, drain days $(p=0.001)$, and the IC intervention period compared to before the intervention period $(p=0.037)$. When restricting the analysis to EVDs, drain days $(p=0.001)$ was the only significant risk factor.

Conclusions Strict adherence to IC, shortening drain duration, and avoiding unnecessary opening and manipulation of the drains are crucial to preventing neurosurgical drain infections.
\end{abstract}

Keywords External ventricular drainage (EVD) $\cdot$ Lumbar drainage (LD) $\cdot$ Intracranial pressure (ICP) $\cdot$ Infection $\cdot$ Risk factors

This article is part of the Topical Collection on Infection

Electronic supplementary material The online version of this article (https://doi.org/10.1007/s00701-019-03801-y) contains supplementary material, which is available to authorized users.

Khetam Hussein

k_hussein@ rambam.health.gov.il

1 Infectious Diseases Institute, Rambam Health Care Campus, P.O. Box 9602, 31096 Haifa, Israel

2 Rappaport Faculty of Medicine, Technion-Israel Institute of Technology, Haifa, Israel

3 Department of Neurosurgery, Rambam Health Care Campus, Haifa, Israel

\section{Background}

Devices such as external ventricular drain (EVD), intracranial pressure (ICP), and lumbar drain (LD) are crucial for the management of elevated ICP, hemorrhage, and monitoring in neurosurgical patients [18]. These devices, while lifesaving, also carry significant complications, including hemorrhage, misplacement, blockage and, most significantly, infections. EVD-related infections may arise from catheter colonization by inoculation of skin flora during insertion or from the manipulation of the drainage system during the postoperative period [34].

The estimated ventriculostomy-related infection incidence rates range between 0 and $27 \%[9,12,22,26,28]$, the wide range being both real and artefactual due to differences in infection definitions. A few previous studies have addressed LD-related infection and rates ranging from 3 to $10 \%[28,29]$. 
Device-related infections present typically as meningitis caused by pathogens common to other post-neurosurgical meningitis [31] and infrequently as other central nervous system (CNS) infections. These infections are associated with high rates of morbidity and mortality, significantly prolonging hospital stay, increasing costs, and often negatively affecting the overall prognosis $[20,23,34]$.

The aims of our study were to examine the risk factors for central nervous system (CNS) infections among patients with CSF drains by type of drain (EVD, ICP, LD) and to assess the effects on an infection control intervention targeting improved management of CSF drains.

\section{Methods}

Design and study participants We conducted a prospective observational cohort study including all consecutive adult patients undergoing insertion of EVD, ICP monitor, and LD in the neurosurgical intensive care unit (ICU) at Rambam Health Care Campus between October 2014 and June 2017. The hospital serves as a primary and referral center for the north of Israel. The Neurosurgery Department at Rambam has 1630 admissions and 1240 surgical procedures yearly, with 12 ICU beds. Follow-up started at the time of catheter insertion and continued until discharge from the neurosurgical ICU or death.

Exposure Between March and August 2016, the Infection Control Unit conducted an intervention, starting with the publication and implementation of local guidelines for CNS device insertion and maintenance (Supplement 1). In addition, contact isolation of multidrug-resistant (MDR) bacteria was revised, introducing cohorting of MDR carriers in one section of the neurosurgical ICU and a physical separation between MDR carriers and all other patients. The intervention included educational sessions delivered in staff meetings and daily observation of staff adherence to the guidelines, hand hygiene, isolation precaution, and environmental cleanliness. Feedback was sent daily to the nursing and medical department heads.

Outcome (dependent variable) The outcome assessed was device-related infection. Since there are no universally accepted definitions of CNS device-related infections, for the purposes of our study, it was defined as meningitis/ventriculitis in the presence of $\mathrm{EVD} / \mathrm{LD} / \mathrm{ICP}$, or within 30 days after its removal if no intervening surgical procedure was performed. Meningitis/ventriculitis was defined using the CDC/NHSN surveillance definition for healthcare-associated infections, which is based on positive cultures, clinical symptoms, and laboratory findings [11]. In the case of Staphylococcus epidermidis, the diagnosis was made if there were at least two positive separate cultures. The incidence of device- related infection was expressed per catheter day, as previously reported $[2,8,29]$, applying similar rules regarding multiple drains, such as the CDC/NHSN's Central Line-Associated Bloodstream Infection surveillance definitions [14].

Independent risk factors Data were collected on risk factors for infection, including the following:

1. Baseline patient characteristics: age, gender, admission neurosurgical diagnosis, previous hospitalization in the 90 days before current admission, home vs. long-term care facility dwell, previous neurosurgery, underlying diseases, Charlson's score [7], CSF leak, presence of CNS foreign body or VP shunt prior to catheter insertion, previous CNS drain, presence of permanent urinary catheter prior to admission, presence of other catheters, and length of stay before drain insertion

2. Procedure characteristics: reason for device insertion, place and date of insertion, antimicrobial prophylaxis, length of procedure, type of catheter, and incision closure type

3. Device management: use of a closed system, type of drainage bag, number of CSF samplings from the catheter, date of catheter removal, and reason for catheter removal

4. Infection control: Adherence to the infection control guidelines for device insertion and maintenance, hand hygiene, standard precautions, and contact isolation

5. Device-related infection and other outcomes: CSF findings including Gram stain and culture, systemic symptoms at time of infection diagnosis, systemic and intrathecal antibiotic treatment, and type and days of antibiotic treatment. In addition, we documented the total length of hospital stay and all-cause in-hospital mortality.

Patient management and data collection Data were collected prospectively by an infection control nurse and as part of the infection control activities in the department and were complemented by a review of patients' computerized charts. EVDs and ICPs were inserted in the operating room, while most LDs were inserted on the ward at bedside. Meningitis was managed according to published and local guidelines, the latter considering the local epidemiology [13, 35].

Statistical analysis We calculated the incidence of device-related infections as the number of device-related infections per catheterday for the study period overall and per catheter type (EVD, LD, ICP), and before, during, and after the infection control intervention. We assessed risk factors for device-related infection, comprising the exposure coded as the period before the intervention, the intervention period, and after the intervention. In the primary analysis, the counting unit was the patient, assessing the first 
catheter insertion per patient. In a secondary analysis, the counting unit was catheters, assessing separately each catheter per patient, overall and for EVDs alone. In the catheter-based analysis, for patients having concomitantly two catheters, we counted the highest risk catheter, ranked as EVD > LD > ICP. Normally distributed continuous variables were expressed as means \pm SD and compared by Student's $t$ test; skewed variables were expressed as medians with IQRs and compared using the Mann-Whitney $U$ test. Categorical data were compared using the chi-square test or Fisher's exact test as appropriate. We entered variables found significant on univariate analysis and noncorrelated statistically and clinically to a backward stepwise logistic regression model to define variables associated independently with device-related infections. Adjusted odds ratios (OR) with $95 \%$ confidence intervals $(\mathrm{CI})$ are reported. Data were analyzed using SPSS V23.

\section{Results}

During the study period, 232 patients were included, 167 (72\%) of whom were males. Mean age was $50 \pm 20$ years. The causes of admission were trauma $(126,54.3 \%)$, infection $(13,5.6 \%)$, and other causes $(93,40.1 \%)$, including spontaneous hemorrhage, brain tumors, and hydrocephalus.

The patients received 437 drains. Of these, 212 were EVDs, 92 were LDs, and 133 were ICPs. Indications for drain insertion included hydrocephalus/increased ICP $(124,28.4 \%)$, trauma $(167,38.2 \%)$, intracerebral hemorrhage $(55,12.6 \%)$, subarachnoid hemorrhage $(45,10.3 \%)$, infection $(29,6.6 \%)$, and CSF leak (17/437, 3.9\%). Fifty-three episodes (12\%) of meningitis (in 38 patients) were identified with a rate of 13.7 episodes per 1000 drain days. In the period preceding the IC intervention, the rate was 17.3 per 1000 drain days; during the intervention, the rate dropped to $7.9 / 1000$, increasing slightly after the intervention to $9.2 / 1000$ drain days. A microbiological diagnosis was confirmed in $34(64 \%)$ of the cases. The majority of cases $(24,70.5 \%)$ were due to Gram-negative bacteria including carbapenem-resistant Acinetobacter baumannii (13, 38.2\%), Klebsiella pneumoniae (9, 26.5\%), and Pseudomonas aeruginosa (2, 5.9\%). Three of the episodes with Acinetobacter baumannii were polymicrobial (Enterobacter sp., Enterococcus faecalis and Staphylococcus epidermidis). Other pathogens included Staphylococcus epidermidis (4, 11.8\%), Candida sp. (3, 8.8\%), Staphylococcus aureus (1 MSSA, 1 MRSA, 5.9\%), and Enterococcus faecalis $(1,2.9 \%)$. The 30-day mortality rate $7.5 \%(4 / 53)$.

\section{Analysis per patient}

In the analysis of the first catheter insertion per patient $(25$ patients with meningitis), risk factors for infection on univariate analysis included diabetes mellitus $(p=0.006)$, Charlson's score $>2(p=0.045)$, CSF leak present before catheter insertion $(p=0.029)$, drain type (EVD > LD > ICP, $p=0.007)$, drain opening $(p<0.005)$, and drain days $(p<0.005)$ (Table 1). Variables remaining significant on multivariate analysis included diabetes mellitus, CSF leak, drain opening, and drain days (Table 2).

\section{Analysis per catheter, all catheters}

On univariate analysis, taking the catheter as the observation unit (53 episodes of meningitis), risk factors for device-related infection included diabetes mellitus $(p=0.016)$, hospitalization in the 90 days before current admission $(p=0.021)$, length of stay before drain insertion $(p=0.045)$, drain type (EVD $>$ ICP and LD, $p=0.002)$, drain opening $(p<0.005)$, and the study period (before intervention, intervention period, and after intervention, $p=0.024$ ) (Table 3). On multivariate analysis, the significant risk factors retained in the final model were drain days, drain opening, and the infection control intervention period compared to before the intervention (OR $0.3,95 \%$ CI $0.09-0.93)$. The odds for meningitis were nonsignificantly lower in the period after the intervention compared to the baseline period before (OR $0.57,95 \%$ CI 0.24 1.33) (Table 2).

\section{Analysis per catheter, EVD only}

Restricting the analysis to EVDs, infection incidence decreased from 18.7/1000 EVD days (29 cases) before the intervention to 9.5/1000 EVD days (4 cases) during the intervention and 8.6/1000 EVD days (4 cases) post-intervention. On univariate analysis, diabetes mellitus (0.028), drain number (0.047), drain insertion in the first three hospitalization days $(0.044)$, drain opening $(<0.005)$, and drain days $(<0.005)$ were associated with the occurrence of meningitis (Supplementary Table 1). In the adjusted analysis, drain days was the only statistically significant risk factor. The odds for meningitis were non-significantly lower during (OR 0.38 , 95\% CI 0.11-1.29) and after (OR 0.38, 95\% CI 0.12-1.26) the IC intervention.

\section{Discussion}

In this study, we assessed risk factors for neurosurgical drain infections. In all analyses, drain days and drain opening were significant risk factors. When assessing the first catheter inserted per patient, diabetes mellitus and CSF leak were significantly related to infection. Taking into account all drains, the IC intervention was significantly associated with the risk for drain-related infections. 
Table 1 Risk factors for meningitis/ventriculitis per patient, first catheter

\begin{tabular}{|c|c|c|c|}
\hline Variable & No meningitis (207) & Meningitis (25) & $P$ value \\
\hline \multicolumn{4}{|l|}{ Demography/background } \\
\hline Gender (male) & $149(72 \%)$ & $18(72 \%)$ & 0.998 \\
\hline Age, mean (range) & $49 \pm 20(14-91)$ & $53 \pm 19(17-83)$ & 0.328 \\
\hline Diabetes mellitus & $35(16.9 \%)$ & $10(40 \%)$ & 0.006 \\
\hline Malignancy & $20(9.9 \%)$ & $3(12 \%)$ & 0.737 \\
\hline Immunosuppression & $20(9.7 \%)$ & $2(8 \%)$ & 0.789 \\
\hline Charlson score $(>2)$ & $81(39.1 \%)$ & $15(60 \%)$ & 0.045 \\
\hline Permanent urinary catheter & $2(1 \%)$ & $0(0 \%)$ & 1 \\
\hline Recent hospitalization (90 days) & $19(9.2 \%)$ & $4(16 \%)$ & 0.281 \\
\hline Recent neurosurgery (90 days) & $17(8.2 \%)$ & $2(8 \%)$ & 0.971 \\
\hline CSF leak before & $4(1.9 \%)$ & $3(12 \%)$ & 0.029 \\
\hline $\begin{array}{l}\text { Foreign body (including VP shunt) in place } \\
\text { before insertion of drain }\end{array}$ & $5(2.4 \%)$ & $0(0 \%)$ & 1 \\
\hline Drain insertion before current drain & $16(7.7 \%)$ & $0(0 \%)$ & 0.229 \\
\hline Diagnosis on admission & & & 0.680 \\
\hline Trauma & $114(55.1 \%)$ & $12(48 \%)$ & \\
\hline Infection & $12(5.8 \%)$ & $1(4 \%)$ & \\
\hline Other & $81(39.1 \%)$ & $12(48 \%)$ & \\
\hline Length of stay before drain insertion-median (IQRs) & $1(1-2)$ & $1(1-2)$ & 0.182 \\
\hline \multicolumn{4}{|l|}{ Operation/catheter data } \\
\hline Drain type & & & 0.007 \\
\hline EVD & $90(43.5 \%)$ & $14(56 \%)$ & \\
\hline LD & $8(3.9 \%)$ & $4(16 \%)$ & \\
\hline ICP & $109(52.7 \%)$ & $7(28 \%)$ & \\
\hline Insertion in operating room & $198(95.7 \%)$ & $22(88 \%)$ & 0.103 \\
\hline Antibiotic prophylaxis or treatment & $199(96.1 \%)$ & $23(92 \%)$ & 0.473 \\
\hline Biovac vs other & $152(74.9 \%)$ & $21(87.5 \%)$ & 0.170 \\
\hline Shift of insertion (evening or night) & $138(70.1 \%)$ & $13(59.1 \%)$ & 0.292 \\
\hline Insertion in the first 3 days after admission & $1899(1.3 \%)$ & $21(84 \%)$ & 0.239 \\
\hline Drain number & & & 0.606 \\
\hline First & $199(96.1 \%)$ & $25(100 \%)$ & \\
\hline Second & $6(2.9 \%)$ & $0(0 \%)$ & \\
\hline Third or more & $2(1 \%)$ & $0(0 \%)$ & \\
\hline Operation duration-median (minutes) (IQRs) & $67(35-138)$ & $43(27-150)$ & 0.180 \\
\hline \multicolumn{4}{|l|}{ Catheter management } \\
\hline Drain opening & $63(30.4 \%)$ & $18(72 \%)$ & $<0.005$ \\
\hline Drain days-median (IQRs) & $6(4-9)$ & $10(7-16)$ & $<0.005$ \\
\hline Infection control intervention: & & & 0.365 \\
\hline Before & $110(53.1 \%)$ & $17(68 \%)$ & \\
\hline Intervention & $33(15.9 \%)$ & $3(12 \%)$ & \\
\hline After & $64(30.9 \%)$ & $5(20 \%)$ & \\
\hline
\end{tabular}

Several previous studies assessed risk factors for infections related to neurosurgical drains, mainly for EVD, and a few assessed LD or ICP also [1, 2, 5, 6, 9, 10, 24, 25, 30, 33, 37]. Most studies are retrospective and limited by a small number of outcome events, limiting complete adjustment of multiple risk factors. Risk factors for EVD-related infection included the duration of the drain $[1,2,9,10,22,25,28,30,33]$, intracerebral hemorrhage with intraventricular hemorrhage [22], concurrent systemic infections [6, 33], multiple drains [25], drain type (LD in a study assessing EVDs and LDs) [29], neurosurgical procedures after drain insertion [37], previous meningo-ventriculitis [29], neoplasm [29], drain insertion outside operation room [6], CSF leakage [28], and frequent manipulation of the EVD system [22]. As for LDs, risk factors for 
Table 2 Risk factors for devicerelated meningitis, on multivariable analysis

\begin{tabular}{|c|c|c|}
\hline Variable & Odds ratio ( $95 \%$ confidence intervals) & $P$ value \\
\hline \multicolumn{3}{|c|}{ Analysis per patient $(N=232)^{\mathrm{a}}$} \\
\hline Diabetes mellitus & $3.281(1.234-8.725)$ & 0.017 \\
\hline CSF leak & $7.359(1.187-45.628)$ & 0.032 \\
\hline Drain opening & $3.309(1.147-9.550)$ & 0.027 \\
\hline Drain days & $1.074(1.005-1149)$ & 0.035 \\
\hline \multicolumn{3}{|c|}{ Analysis per catheter, all catheters $(N=437)^{\mathrm{b}}$} \\
\hline Drain days $\mathrm{s}^{\mathrm{a}}$ & $1.097(1.050-1.146)$ & $<0.001$ \\
\hline Drain opening & $3.825(1.698-8.617)$ & 0.001 \\
\hline \multicolumn{3}{|c|}{ Infection control intervention: } \\
\hline Before intervention & Reference & \\
\hline Intervention period & $0.295(0.093-0.930)$ & 0.037 \\
\hline After intervention & $0.567(0.241-1.334)$ & 0.194 \\
\hline \multicolumn{3}{|c|}{ Analysis per catheter, EVD only $(N=212)^{\mathrm{c}}$} \\
\hline Drain opening & $3.480(0.948-12.771)$ & 0.060 \\
\hline Drain days & $1.094(1.040-1.152)$ & 0.001 \\
\hline \multicolumn{3}{|c|}{ Infection control intervention: } \\
\hline Before intervention & Reference & \\
\hline Intervention period & $0.380(0.112-1.288)$ & 0.120 \\
\hline After intervention & $0.382(0.116-1.256)$ & 0.113 \\
\hline \multicolumn{3}{|c|}{$\begin{array}{l}{ }^{a} \text { Drain type and the study period were entered to the regression but not retained in the final equation. Hosmer } \\
\text { Lemeshow } p=0.098\end{array}$} \\
\hline \multicolumn{3}{|c|}{$\begin{array}{l}{ }^{\mathrm{b}} \text { Variables entered to the regression but not retained in the final equation were diabetes mellitus, recent hospital- } \\
\text { ization, length of stay before drain insertion, and drain type. Hosmer Lemeshow } p=0.81\end{array}$} \\
\hline
\end{tabular}

infection included site leakage, drain blockage, and drain duration $[19,28]$. Our study was prospective and assessed all three types of drains. We did not attempt to assess the effect of a single intervention but assessed a bundle of interventions, recognizing that single manipulations in catheter management cannot reduce infection rates. We show that a coordinated effort, addressing catheter insertion, opening, and replacement and IC was associated with lower infection rates, adjusting to other risk factors.

The association between drain duration and infection was observed in many of the previous studies [1, 2, 9, 10, 22, 25, $28,30,33$ ]. The cutoff defining an increased risk for infection is debated. EVD duration $>10$ days was the time point identified for an increased risk in a recent retrospective matched case-control study [33]. In earlier studies, including a review summarizing 17 studies [20], the authors observed a gradual daily increase in infection rate, peaking at 9-11 days [20]. Similarly, Holloway et al. found that the risk increased in the first 10 days but decreased significantly thereafter [10]. In a study that included EVD and LD drains, duration $>15$ days increased the risk for infection seven times compared to drains with a shorter duration [28]. Other studies pointed at 5-6-day duration as the cutoff for increased risk for infection [10, 22].
A precise cutoff probably does not exist, as the risk increases from day to day. Variations between studies may reflect local practices in each center and the timing of infection inoculation: during EVD insertion or during daily handling and maintenance.

During an IC intervention to improve staff adherence to IC practices, we observed that the infection rate decreased from 17.3 per 1000 drain days before the intervention to $7.9 / 1000$ after the intervention. Our rate of EVD-related meningitis specifically, during and following the intervention period (9.5$8.6 / 1000$ EVD days), was in the low range of rates in previous studies reporting on EVD-related meningitis per catheter day (4.8-17.2/1000 EVD days) in the UK and Ireland [12], Russia [27], and Switzerland [32]. In the analysis per patient, patientrelated factors dominated, while the effect of the IC intervention was observed in the analysis per catheter. Improvement of adherence to EVD insertion and management protocols or bundles to lower drain-related complications have been shown previously to reduce infection rates $[2,3,16,17,21]$. As for all bundle interventions, it is difficult to point at the precise component/s of the bundle that were effective. The IC intervention included two of the dominant risk factors in our study, attention to drain duration and reduction of unnecessary drain 
Table 3 Risk factors for meningitis/ventriculitis per catheter, all catheters

\begin{tabular}{|c|c|c|c|}
\hline Variable & No meningitis (384) & Meningitis (53) & $P$ value \\
\hline \multicolumn{4}{|l|}{ Demography/background } \\
\hline Gender (male) & $265(69 \%)$ & $38(71.7 \%)$ & 0.691 \\
\hline Age, median (range) & $49 \pm 20(14-91)$ & $46 \pm 22(17-83)$ & \\
\hline Diabetes mellitus & $69(18 \%)$ & $17(32 \%)$ & 0.016 \\
\hline Malignancy & $34(9 \%)$ & $6(11.3 \%)$ & 0.58 \\
\hline Immunosuppression & $34(8.9 \%)$ & $4(7.5 \%)$ & 0.752 \\
\hline Charlson score $(>2)$ & $151(39.3 \%)$ & $24(45.3 \%)$ & 0.406 \\
\hline Permanent urinary catheter & $15(3.9)$ & $3(5.7 \%)$ & 0.469 \\
\hline Recent hospitalization (90 days) & $49(12.8 \%)$ & $13(24.5 \%)$ & 0.021 \\
\hline Recent neurosurgery (90 days) & $185(48.2 \%)$ & $30(56.6 \%)$ & 0.25 \\
\hline CSF leak before & $18(4.7 \%)$ & $3(5.7 \%)$ & 0.731 \\
\hline Foreign body before & $79(20.6 \%)$ & $17(32.1 \%)$ & 0.058 \\
\hline VP shunt before & $12(3.1 \%)$ & $1(1.9 \%)$ & 0.617 \\
\hline Drain insertion before current drain & $181(47.1 \%)$ & $27(50.9 \%)$ & 0.603 \\
\hline Diagnosis on admission & & & 0.589 \\
\hline Trauma & $185(48.2 \%)$ & $23(43.4 \%)$ & \\
\hline Infection & $29(7.6 \%)$ & $6(11.3 \%)$ & \\
\hline Other & $170(44.3 \%)$ & $24(45.3 \%)$ & \\
\hline Length of stay before drain insertion & $2(1-16.5)$ & $5(1-22)$ & 0.045 \\
\hline \multicolumn{4}{|l|}{ Operation/catheter data } \\
\hline Drain type & & & 0.002 \\
\hline EVD & $175(45.6 \%)$ & $37(69.8 \%)$ & \\
\hline LD & $83(21.6 \%)$ & $9(17 \%)$ & \\
\hline ICP & $126(32.8 \%)$ & $7(13.2 \%)$ & \\
\hline Insertion in operating room & $294(76.6 \%)$ & $44(83 \%)$ & 0.293 \\
\hline Antibiotic prophylaxis or treatment & $331(86.2 \%)$ & $46(86.6 \%)$ & 0.906 \\
\hline Biovac vs other & $299 / 358(83.5 \%)$ & $46 / 49(93.9 \%)$ & 0.058 \\
\hline Shift of insertion (evening or night) & $201 / 299(67.7 \%)$ & $29 / 44(65.9 \%)$ & 0.815 \\
\hline Insertion in the first 3 days after admission & $223(58.1 \%)$ & $22(41.5 \%)$ & 0.023 \\
\hline Drain number & & & 0.2 \\
\hline First & $209(54.4 \%)$ & $26(49.1 \%)$ & \\
\hline Second & $80(20.8 \%)$ & $8(15.1 \%)$ & \\
\hline Third or more & $95(24.7 \%)$ & $19(35.8 \%)$ & \\
\hline Operation duration (minutes) - median (IQRs) & $57(33-134)$ & $37(31-52)$ & 0.01 \\
\hline \multicolumn{4}{|l|}{ Catheter management } \\
\hline Drain opening & $148(38.5 \%)$ & $44(83 \%)$ & $<0.005$ \\
\hline Drain days median (IQRs) & $6(4-10)$ & $13(9-18)$ & $<0.005$ \\
\hline Infection control intervention: & & & 0.024 \\
\hline Before & $222(57.8 \%)$ & $41(77.4 \%)$ & \\
\hline Intervention & $60(15.6 \%)$ & $4(7.5 \%)$ & \\
\hline After & $102(26.6 \%)$ & $8(15.1 \%)$ & \\
\hline
\end{tabular}

openings and replacements. However, since the study period was associated with lower infection rates independent of these risk factors, additional components of the bundle must have contributed to lowering the infection rates. A trend towards increasing infection rates after the intervention, if true, might be due to relaxation of the monitoring and education activities and points at the need for continued intense efforts to maintain infection control achievements.

Previous studies showed Gram-positive bacteria, mainly coagulase negative Staphylococci, to be the main pathogens causing neurosurgical drain-related infection $[8,15,19,28$, $29,33,36,37]$. In the current study, there was a predominance of Gram-negative bacteria, especially carbapenem-resistant 
Acinetobacter baumannii. The emergence of Gram-negative pathogens as the main pathogen was reported in postneurosurgical meningitis $[2,4]$. It reflects the changing epidemiology of nosocomial infections and the emergence of MDR Gram-negative pathogens as a major threat for healthcare institutions. We show that an IC intervention can affect infection rates when infections are caused by MDR Gram-negative bacteria.

The main limitation of our study is that it was conducted in a single center. The methodologically correct analysis is per patient. However, the analysis by catheter, counting patients more than once in the analysis, allowed us to better inspect variables related the individual catheter insertion and maintenance. We did not adjust for clustering in the catheter-based analysis. We did not perform a time series analysis, due to low outcome event-rates; however, the cohort design allowed us to adjust the study period to important risk factors for devicerelated meningitis. Other healthcare-associated infections, including central-venous catheter infections and ventilatorassociated pneumonia, were not surveilled during the study period.

In conclusion, strict adherence to infection control is mandatory to prevent neurosurgical drain infections. Shortening drain duration and avoiding unnecessary opening and manipulation of the drains are crucial to preventing drain-related infections. This requires coordination and collaboration of the neurosurgical and IC teams.

Funding No funding was received for this research.

\section{Compliance with ethical standards}

Conflict of interest The authors declare that they have no conflict of interest.

Ethical approval All procedures performed in studies involving human participants were in accordance with the ethical standards of the institutional and/or national research committee (Helsinki Committee, Rambam Medical Center) and with the 1964 Helsinki declaration and its later amendments or comparable ethical standards. For this type of study formal consent was not required.

Publisher's note Springer Nature remains neutral with regard to jurisdictional claims in published maps and institutional affiliations.

\section{References}

1. Aucoin PJ, Kotilainen HR, Gantz NM, Davidson R, Kellogg P, Stone B (1986) Intracranial pressure monitors. Epidemiologic study of risk factors and infections. Am J Med 80:369-376

2. Camacho EF, Boszczowski I, Basso M, Jeng BC, Freire MP, Guimarães T, Teixeira MJ, Costa SF (2011) Infection rate and risk factors associated with infections related to external ventricular drain. Infection 39:47-51. https://doi.org/10.1007/s15010-0100073-5

3. Chatzi M, Karvouniaris M, Makris D, Tsimitrea E, Gatos C, Tasiou A, Mantzarlis K, Fountas KN, Zakynthinos E (2014) Bundle of measures for external cerebral ventricular drainage-associated ventriculitis. Crit Care Med 42:66-73. https://doi.org/10.1097/ CCM.0b013e31829a70a5

4. Chen C, Chang C, Lin L, Chen WL, Chang YJ, Wang SH, Cheng CY, Yen HC (2016) Risk factors associated with postcraniotomy meningitis: a retrospective study. Medicine (Baltimore) 95:e4329. https://doi.org/10.1097/MD.0000000000004329

5. Clark WC, Muhlbauer MS, Lowrey R, Hartman M, Ray MW, Watridge CB (1989) Complications of intracranial pressure monitoring in trauma patients. Neurosurgery 25:20-24

6. Citerio G, Signorini L, Bronco A, Vargiolu A, Rota M, Latronico N (2015) External ventricular and lumbar drain device infections in ICU patients. Crit Care Med 43:1630-1637. https://doi.org/10. 1097/CCM.0000000000001019

7. D'Hoore W, Sicotte C, Tilquin C (1993) Risk adjustment in outcome assessment: the Charlson comorbidity index. Methods Inf Med 32:382-387

8. Hagel S, Bruns T, Pletz MW, Engel C, Kalff R, Ewald C (2014) External ventricular drain infections: risk factors and outcome. Interdiscip Perspect Infect Dis 2014:708531. https://doi.org/10. 1155/2014/708531

9. Hoefnagel D, Dammers R, Ter Laak-Poort MP, Avezaat CJJ (2008) Risk factors for infections related to external ventricular drainage. Acta Neurochir 150:209-214. https://doi.org/10.1007/s00701-0071458-9

10. Holloway KL, Barnes T, Choi S, Bullock R, Marshall LF, Eisenberg HM, ane JA, Ward JD, Young HF, Marmarou A (1996) Ventriculostomy infections: the effect of monitoring duration and catheter exchange in 584 patients. J Neurosurg 85:419424

11. Horan TC, Andrus M, Dudeck MA (2008) CDC/NHSN surveillance definition of health care-associated infection and criteria for specific types of infections in the acute care setting. Am J Infect Control 36:309-332. https://doi.org/10.1016/j.ajic.2008.03.002

12. Humphreys H, Jenks P, Wilson J, Weston V, Bayston R, Waterhouse C, Moore A, Healthcare Infection Society Working Party on Neurosurgical Infections (2017) Surveillance of infection associated with external ventricular drains: proposed methodology and results from a pilot study. J Hosp Infect 95:154-160. https:// doi.org/10.1016/j.jhin.2016.09.008

13. Hussein K, Bitterman R, Shofty B, Paul M, Neuberger A (2017) Management of post-neurosurgical meningitis: narrative review. Clin Microbiol Infect 23:621-628. https://doi.org/10.1016/j.cmi. 2017.05.013

14. Infections $\mathrm{C}$. $\mathrm{CDC} / \mathrm{NHSH}$ bloodstream infection event (central line-associated bloodstream infection and non-central line-associated bloodstream infection). Centers dis control Prev Natl Healthc Saf network 2015;(last accessed January 2018) www.cdc.gov/nhsn/ PDFs/pscManual/4PSC_CLABScurrent

15. Kim J-H, Desai NS, Ricci J, Stieg PE, Rosengart AJ, Härtl R, Fraser JF (2012) Factors contributing to ventriculostomy infection. World Neurosurg 77:135-140. https://doi.org/10.1016/j.wneu.2011.04. 017

16. Korinek A-M, Baugnon T, Golmard J-L, van Effenterre R, Coriat P, Puybasset L (2006) Risk factors for adult nosocomial meningitis after craniotomy role of antibiotic prophylaxis. Neurosurgery 59: 126-133. https://doi.org/10.1227/01.neu.0000243291.61566.21

17. Kubilay Z, Amini S, Fauerbach LL, Archibald L, Friedman WA, Layon AJ (2013) Decreasing ventricular infections through the use of a ventriculostomy placement bundle: experience at a single institution. J Neurosurg 118:514-520. https://doi.org/10.3171/2012. 11.JNS121336 
18. Lane PL, Skoretz TG, Doig G, Girotti MJ (2000) Intracranial pressure monitoring and outcomes after traumatic brain injury. Can $\mathrm{J}$ Surg 43:442-448

19. Liang H, Zhang L, Gao A, Li Y, Jiang Z, Hu F, Shao B, Liu Y, Zhang X (2016) Risk factors for infections related to lumbar drainage in spontaneous subarachnoid hemorrhage. Neurocrit Care 25: 243-249. https://doi.org/10.1007/s12028-015-0239-1

20. Lozier AP, Sciacca RR, Romagnoli MF, Connolly ES Jr (2008) Ventriculostomy-related infections. Neurosurgery 62(Suppl 2): 688-700. https://doi.org/10.1227/01.neu.0000316273.35833.7c

21. Lwin S, Low SW, Choy DKS, Yeo TT, Chou N (2012) External ventricular drain infections: successful implementation of strategies to reduce infection rate. Singap Med J 53:255-259

22. Mayhall CG, Archer NH, Lamb VA, Spadora AC, Baggett JW, Ward JD, Narayan RK (1984) Ventriculostomy-related infections. A prospective epidemiologic study. N Engl J Med 310:553-559

23. Neuberger A, Shofty B, Bishop B, Naffaa ME, Binawi T, Babich T, Rappaport ZH, Zaaroor M, Sviri G, Yahav D, Paul M (2016) Risk factors associated with death or neurological deterioration among patients with gram-negative postneurosurgical meningitis. Clin Microbiol Infect 22:573.e1-573.e4. https://doi.org/10.1016/j.cmi. 2016.03.016

24. Park J, Choi Y, Ohk B, Chang H (2017) Cerebrospinal fluid leak at percutaneous exit of ventricular catheter as a crucial risk factor for external ventricular drainage-related infection in adult neurosurgical patients. World Neurosurg:1-6. https://doi.org/10.1016/j.wneu. 2017.09.190

25. Phan K, Schultz K, Huang C, Halcrow S, Fuller J, McDowell D, Mews PJ, Rao PJ (2016) External ventricular drain infections at the Canberra hospital : a retrospective study. J Clin Neurosci 32:95-98. https://doi.org/10.1016/j.jocn.2016.03.019

26. Poblete R, Zheng L, Raghavan R, Cen S, Amar A, Sanossian N, Mack W, Kim-Tenser M (2017) Trends in ventriculostomyassociated infections and mortality in aneurysmal subarachnoid hemorrhage: data from the Nationwide inpatient sample. World Neurosurg 99:599-604. https://doi.org/10.1016/j.wneu.2016.12. 073

27. Savin I, Ershova K, Kurdyumova N, Ershova O, Khomenko O, Danilov G, Shifrin M, Zelman V (2018) Healthcare-associated ventriculitis and meningitis in a neuro-ICU: incidence and risk factors selected by machine learning approach. J Crit Care 45:95-104. https://doi.org/10.1016/J.JCRC.2018.01.022

28. Schade RP, Schinkel J, Visser LG, van Dijk JMC, Voormolen JHC, Kuijper EJ (2005) Bacterial meningitis caused by the use of ventricular or lumbar cerebrospinal fluid catheters. J Neurosurg 102: 229-234. https://doi.org/10.3171/jns.2005.102.2.0229

29. Scheithauer S, Bürgel U, Bickenbach J, Häfner H, Haase G, Waitschies B, Reinges MH, Lemmen SW (2010) External ventricular and lumbar drainage-associated meningoventriculitis: prospective analysis of time-dependent infection rates and risk factor analysis. Infection 38:205-209. https://doi.org/10.1007/s15010-0100006-3
30. Schultz M, Moore K, Foote AW (1993) Bacterial ventriculitis and duration of ventriculostomy catheter insertion. J Neurosci Nurs 25: $158-164$

31. Shofty B, Neuberger A, Naffaa ME, Binawi T, Babitch T, Rappaport ZH, Zaaroor M, Sviri G, Paul M (2016) Intrathecal or intraventricular therapy for post-neurosurgical gram-negative meningitis: matched cohort study. Clin Microbiol Infect 22:66-70. https://doi.org/10.1016/j.cmi.2015.09.023

32. Strahm C, Albrich WC, Zdravkovic V, Schöbi B, Hildebrandt G, Schlegel M (2018) Infection rate after cranial neurosurgical procedures: a prospective single-center study. World Neurosurg 111: e277-e285. https://doi.org/10.1016/j.wneu.2017.12.062

33. Thompson DR, Vlachos S, Patel S, Innocent S, Tolias C, Barkas K (2018) Recurrent sampling and ventriculostomy-associated infections: a case-control study. Acta Neurochir 160:1089-1096. https:// doi.org/10.1007/s00701-018-3508-x

34. Tsang ACO, Leung GKK (2011) External ventricular drain infections. www.intechopen.com

35. Tunkel AR, Hasbun R, Bhimraj A, Byers K, Kaplan SL, Scheld MW, van de Beek D, Bleck TP, Garton HJ, Zunt JR (2017) 2017 Infectious Diseases Society of America's clinical practice guidelines for healthcare-associated ventriculitis and meningitis. Clin Infect Dis 64:e34-e65. https://doi.org/10.1093/cid/ciw861

36. Walti LN, Conen A, Coward J, Jost GF, Trampuz A (2013) Characteristics of infections associated with external ventricular drains of cerebrospinal fluid. J Inf Secur 66:424-431. https://doi. org/10.1016/j.jinf.2012.12.010

37. Woo PYM, Wong HT, Pu JKS, Wong WK, Wong LYW, Lee MWY, Yam KY, Lui WM, Poon WS (2017) Moving the goalposts: a comparison of different definitions for primary external ventricular drain infection and its risk factors: a multi-center study of 2575 patients. J Clin Neurosci 45:67-72. https://doi.org/10.1016/j.jocn. 2017.05.042

\section{Comments}

This is a well performed prospective study of the infectious complications of CNS externalized catheters and monitoring devices. The authors identified already known risk factors such as diabetes, duration of catheter presence, and device sampling rates as the prime culprits in increasing infection rates. The favourable effect of simple infection control interventions is an important observation and mirrors the effectiveness of similar protocols in other invasive monitoring procedures as reported in the literature. The health and economic burden of increasingly multi-drug resistant infections due to CNS drains makes the implementation of infection control protocols a no brainer for health care institutions.

Zvi Harry Rappaport

Petah Tiqvah, Israel 